\title{
Dual nitrate isotope constraints on the origin of nutrients in Baffin Bay and in the Labrador Sea
}

\author{
M. KIENAST ${ }^{1 *}$, N. LEHMANN ${ }^{1}$, C. BUCHWALD ${ }^{1}$, S. $^{2}$
} DAVIN $^{1}$, J. GRANGER ${ }^{2}$, O. SHERWOOD ${ }^{3}$

${ }^{1}$ Dept. Oceanography, Dalhousie University, Halifax, NS, Canada (*correspondence: markus.kienast@dal.ca)

${ }^{2}$ Dept. Marine Sciences, University of Connecticut, Groton, CT 06340, USA

${ }^{3}$ Dept. Earth and Environmental Sciences, Dalhousie University, Halifax, NS, Canada

The Canadian Arctic Ocean connects the North Pacific, an area of active denitrification, and the North Atlantic, a region of extensive $\mathrm{N}_{2}$ fixation. Here, we present water column natural abundance nitrogen $(\mathrm{N})$ and oxygen $(\mathrm{O})$ isotope ratios of nitrate $\left(\mathrm{NO}_{3}{ }^{-}\right)$collected throughout the Canadian Archipelago, Baffin Bay and the Labrador Sea. These data shed light on both the origin and internal cycling of $\mathrm{NO}_{3}{ }^{-}$in Baffin Bay and in the Labrador Sea.

Benthic coupled nitrification-denitrification on the Bering and Chukchi shelves and remineralization along the transit across the Chukchi shelf impart a pronounced enrichment in $\delta^{15} \mathrm{~N}$ and a coincident minimum in $\delta^{18} \mathrm{O}$ on the cold Pacific-derived halocline waters observed throughout the study region. The Baffin Island Current and the Labrador Current subsequently carry this ${ }^{15} \mathrm{~N}$ enrichment and relatively low $\delta^{18} \mathrm{O}$ southward along the western Baffin Bay and into the western Labrador Sea.

Elevated $\delta^{15} \mathrm{~N}_{\mathrm{NO} 3}$ and concurrently low $\delta^{18} \mathrm{O}_{\mathrm{NO} 3}$ in the deep/bottom water of Baffin Bay indicate substantial remineralization of surface ocean export production largely fueled by Pacific-derived nutrients. Nutrients supplied to Baffin Bay are hence stripped from surface waters and trapped at depth over long timescales, where sedimentary denitrification further adds to the $\mathrm{N}$ removal capacity of the Arctic Ocean.

The overall trends in $\mathrm{NO}_{3}{ }^{-}$isotope ratios will be discussed in the context of regional circulation patterns and $\mathrm{N}$ biogeochemistry in the Canadian Archipelago and further downstream in the Baffin Bay and Labrador Sea. 